\title{
Primary hydatid cyst of the neck diagnosed by frozen section
}

\author{
Elham Jafari $^{*(\mathbb{D}}$, Mahdieh Shokrizadeh ${ }^{1}$, Mohsen Shahba $^{2}$ \\ ${ }^{1}$ Pathology and Stem Cells Research Center, Kerman University of Medical Sciences, Kerman, Iran \\ ${ }^{2}$ Department of Neurosurgery, Kerman University of Medical Sciences, Kerman, Iran
}

*Corresponding Author: Elham Jafari, Pathology and Stem Cells Research Center, Kerman University of Medical Sciences, Kerman, Iran, Email: ejfarda@yahoo.com

\begin{abstract}
Hydatid cyst develops as a slowly growing cyst in patients infected with echinococcosis, which is caused by larval stages of cestodes (tapeworms) of the genus Echinococcus, and is also known as hydatidosis. Echinococcus granulosus is the most common Echinococcus species involving humans. Echinococcosis can involve any organ. The liver, followed by the lungs, is the most commonly involved organ. Hydatid cyst in the head and neck is so rare that only a few cases have so far been reported. The case reported here is an unusual location of hydatidosis even in countries where echinococcal infection is endemic. She is a 15-year-old girl presenting with asymptomatic cervical cyst. The result of the cervical computed tomography scan was similar to a benign congenital cyst but the frozen section demonstrated a hydatid cyst that was confirmed by final histopathology. We were encouraged to report this case due to the rarity of its location and difference between clinico-radiological presentations and frozen section.

Keywords: Hydatid cyst, Echinococcosis, Computed tomography scan, Frozen section
\end{abstract}

Received: 19 October 2019, Accepted: 9 November 2019, ePublished: 31 December 2019

\section{Introduction}

The cause of cystic hydatid disease (echinococcal disease) is a parasite called Echinococcus granulosus. The definitive hosts of the parasite are dogs, but sheep and other ruminants are the intermediate hosts of the parasite. Humans can also serve as intermediate hosts in which the parasite has the potential to cause hydatid cysts. Hydatid cysts are endemic in certain regions of the world, including Iran (1).

Hydatid cyst develops as a slowly growing cyst in patients infected with echinococcosis, which is caused by larval stages of cestodes (tapeworms) of the genus, and is also known as hydatidosis (2). E. granulosus is the most common Echinococcus species involving humans. Echinococcosis can involve any organ. The liver, followed by the lungs, is the most commonly involved organ. These two organs account for $90 \%$ of cases of echinococcosis (14). Hydatid cyst in the head and neck is so rare that only a few cases have so far been reported (4-10).

\section{Case Report}

The patient is a 15-year-old girl from southeastern Iran having presented with an enlarging asymptomatic cervical mass since one year ago. She had undergone cyst resection. The cyst was located in the suboccipital region, left side of the posterior skull base with downward extension into the left upper neck. Physical examination, including that of the neurological system, revealed no abnormal findings such as cystic hygroma. In the cervical computed tomography scan, a benign congenital cervical cyst was observed (Figure 1). Conventional laboratory tests such as urine analysis, blood count, and biochemical tests were normal. She had undergone cyst resection. The neurosurgeons aspirated the cyst fluid and removed a part of the cyst and sent it to the pathology department for intraoperative consultation. Obviously, it appeared as a creamy cyst with a size of $5.5 \times 5 \times 4 \mathrm{~cm}^{3}$.

Touch imprints and the thin slice of frozen section showed acellular, hyaline, and laminated membrane and an inner nucleated germinal layer with brood capsules and rotoscoliosis (Figure $2 \mathrm{~A}$ and $\mathrm{B}$ ).

The clear aspirated fluid was immediately sent to the laboratory for processing. Both smears and cell block preparation showed detached refractile hooklets and hydatid sands in an amorphous background (Figure 3A). Degenerative rotoscoliosis was also found. Therefore, the diagnosis was a hydatid cyst. The permanent specimen confirmed the diagnosis made by frozen section (Figure 3B). Postoperative evaluation with thoracic, abdominal, and cranial CT scan revealed no evidence of hydatid cyst. The patient was discharged three days later and was advised to receive albendazole.

(c) 2019 The Author(s); Published by Shahrekord University of Medical Sciences. This is an open-access article distributed under the terms of the Creative Commons Attribution License (http://creativecommons.org/licenses/by/4.0), which permits unrestricted use, distribution, and reproduction in any medium, provided the original work is properly cited. 


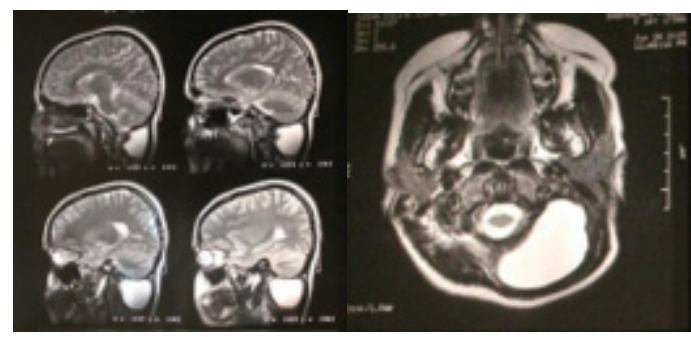

Figure 1. Large cystic structure located in the left side of the posterior skull base.

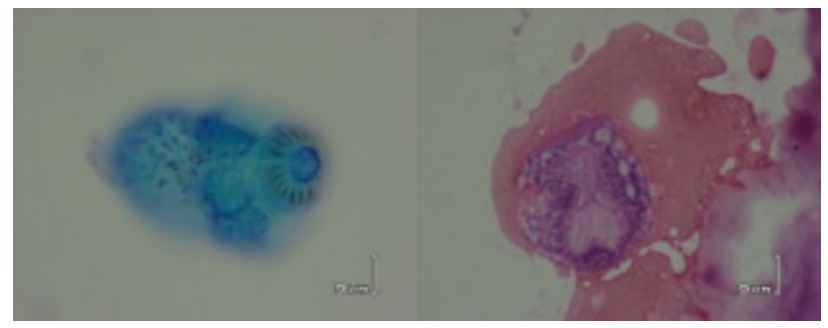

Figure 2. Protoscoleces (A) in touch imprint (Giemsa staining, magnification 400X), (B) in frozen section slide (black arrow) (hematoxylin-eosin staining, magnification 400X).

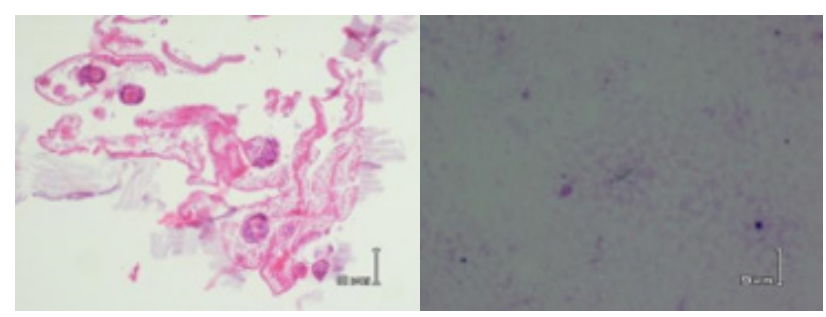

Figure 3. (A) Permanent slide (hematoxylin-eosin staining, magnification 100X): thin laminated membrane with protoscoleces (black arrows), (B) Hooklet and hydatid sand in cell block preparation (hematoxylin-eosin staining, magnification 400X)

\section{Discussion}

Hydatid disease is a zoonotic parasitic infection induced by larvae of the genus Echinococcus and may develop in every organ. Typically, hydatid cyst consists of a single unilocular cyst; however, $20 \%-30 \%$ of the cases may have multiple cysts in one or more organs (8).

The most commonly involved organs are liver, lung, and spleen. The evidence from around the world shows some cases of hydatidosis developed in unusual locations including the spleen, kidney, heart, thyroid gland, ovaries, cranium, and parotid gland; however, hydatid disease involving soft tissue accounts for less than 3\% of all hydatid disease. Moghimi et al reported primary echinococcal cyst in the thyroid gland on the neck CT scan, which was suggestive of a hydatid cyst or cold thyroid nodule and was confirmed by frozen section histology (9). However, its presentation in the neck, especially mimicking congenital cyst, is even rarer (5-7). Therefore, most hydatid cysts of the neck are misdiagnosed. Hydatid cysts usually appear as slowly growing, painless, and fluctuant mass. Imaging greatly assists in the diagnosis of hydatid cyst (10). Hydatid cysts in unusual anatomical locations are difficult to diagnose on imaging, even in patients from endemic regions (11). Diagnosis is considered differential when a cystic lesion is identified in a patient who lives in or has come from an area in which the disease is endemic, especially if the previously described imaging characteristics (e.g., multivesicular cysts, calcification, and intracystic membranes) are seen (1214). Fine needle aspiration cytology (FNAC) is a widely accepted diagnostic technique to study neck mass, but it is not recommended for suspected cases of hydatid cyst because of the likelihood of an acute anaphylactic reaction. In contrast, lack of any complication during FNAC procedure has been frequently reported (15). Special care should be taken not to rupture the cyst during the operation because of the risk of disseminating the infestation as well as the risk of anaphylaxis (9). Specimen collection was conducted by FNAC on our case before cyst removal. Histopathological examination is the best method to make the definitive diagnosis of hydatid cysts. The microscopic observations revealed three layers of the cyst wall. The outer layer, namely pericyst, is a hard protective layer that serves as the host response to the parasite. The middle layer is a white acellular laminated membrane, and the inner germinal layer is translucent and thin (12).

Our case presented with cervical mass mimicking congenital cervical cyst such as cystic hygroma on imaging and was diagnosed by frozen section. The interesting aspect of these hydatid cysts is the lack of development in the lung and liver.

\section{Conclusion}

We concluded that hydatid disease in the sub-occipital region of the neck is rare; however, it should be considered in the differential diagnosis of the cervical cystic lesions as cystic hygroma, especially in endemic countries where hydatid disease is a public health problem.

Conflict of Interests

Nil.

Acknowledgments

The authors would like to thank their colleagues in the Department of Pathology, Bahonar Hospital affiliated with Kerman University of Medical Sciences.

\section{References}

1. Geramizadeh B. Unusual locations of the hydatid cyst: a review from iran. Iran J Med Sci. 2013;38(1):2-14.

2. Polat $\mathrm{P}$, Kantarci $M$, Alper F, Suma $S$, Koruyucu MB, Okur A. Hydatid disease from head to toe. Radiographics. 2003;23(2):475-94. doi: 10.1148/rg.232025704.

3. Ramraj D, Swaroop S, Jagadeesha BVC, Mahesh K. Primary multilocular hydatid cyst of neck: a rare case report. J Evid Based Med Healthc. 2015;2(6):746-50.

4. Adaletli I, Yigiter R, Selcuk D, Sirikci A, Senyuz OF. Primary hydatid cyst of the head and neck diagnosed with ultrasound and computed tomography: a report of two cases. South Med 
J. 2005;98(8):830-2. doi: 10.1097/01.smj.0000170732.24324. ea.

5. Katilmiş H, Oztürkcan S, Ozdemir I, Adadan Güvenç I, Ozturan S. Primary hydatid cyst of the neck. Am J Otolaryngol. 2007;28(3):205-7. doi: 10.1016/j.amjoto.2006.08.007.

6. Dahniya MH, Hanna RM, Ashebu S, Muhtaseb SA, el-Beltagi A, Badr S, et al. The imaging appearances of hydatid disease at some unusual sites. Br J Radiol. 2001;74(879):283-9. doi: 10.1259/bjr.74.879.740283.

7. Eroğlu A1, Atabekoğlu S, Kocaoğlu H. Primary hydatid cyst of the neck. Eur Arch Otorhinolaryngol. 1999;256(4):202-4. doi: 10.1007/s004050050140.

8. Rochdi Y, Raji A, Elhattab Y, Nouri H, Bouchoua F, Narjisse Y, et al. A rare localization of hydatidosis: a cervical hydatid cyst. Fr ORL. 2007;92:315-7.

9. Moghimi M, Kamrava SK, Asghari AM, Heshmatzade Behzadi A, Jalessi M, Naraghi MM, et al. Primary echinococcal cyst in the thyroid gland: a case report from Iran. J Infect Dev Ctries. 2009;3(9):732-4. doi: 10.3855/jidc.172.

10. Cangiotti L, Muiesan P, Begni A, de Cesare V, Pouchè A, Giulini SM, et al. Unusual localizations of hydatid disease: a 18 year experience. G Chir. 1994;15(3):83-6.

11. El Kohen A, Benjelloun A, El Quessar A, Derraz S, Lazrak A, Jazouli N, et al. Multiple hydatid cysts of the neck, the nasopharynx and the skull base revealing cervical vertebral hydatid disease. Int J Pediatr Otorhinolaryngol. 2003;67(6):65562. doi: 10.1016/s0165-5876(03)00059-4.

12. Sultana N, Hashim TK, Jan SY, Khan Z, Malik T, Shah W. Primary cervical hydatid cyst: a rare occurrence. Diagn Pathol. 2012;7:157. doi: 10.1186/1746-1596-7-157.

13. Sureka J, Sarawagi R, Eapen A, Keshava SN, Vedantam R. Skull base hydatid cyst with intracranial extension presenting as vocal cord palsy: a case report. Br J Radiol. 2010;83(987):e679. doi: 10.1259/bjr/21853098.

14. Pedrosa I, Saíz A, Arrazola J, Ferreirós J, Pedrosa CS. Hydatid disease: radiologic and pathologic features and complications. Radiographics. 2000;20(3):795-817. doi: 10.1148/ radiographics.20.3.g00ma06795.

15. Tekin M, Osma U, Yaldiz M, Topcu I. Preauricular hydatid cyst: an unusual location for echinoccosis. Eur Arch Otorhinolaryngol. 2004;261(2):87-9. doi: 10.1007/s00405003-0650-7. 